\title{
Knowledge Management in India : A Case Study of An Indian Bank
}

\section{Chandana Goswami}

\begin{abstract}
Knowledge Management is among one of the buzzwords prevailing in the management circles. It is seen as a tool which can create a strategic impact. Theoretically knowledge management is seen to have the potential to influence many spheres of an organization. It is available in a variety of forms and to a large extent the hidden tacit knowledge can be codified and made explicit. It is believed that by sharing of knowledge, the organization will benefit in the long run. However the success of knowledge management lies in the role played by the organization, the developers and the users themselves. This paper makes an exploratory study about Knowledge Management in practice at ICICI (India) and tries to identify the critical success factors of Knowledge Management. A small survey was done among 31 employees of ICICI and based on their responses a factor analysis was carried out. This resulted in identification of the critical success factors. A personal observation of the system at work also makes attempt to understand whether Knowledge Management can fulfill some of the needs of the technical and professional workforce.
\end{abstract}

KEYWORDS : Knowledge Management, India, ICICI, initiating, implementing, iacit, explicit

\section{Why 'Knowledge Management'?}

Knowledge Management (KM) has been in existence in our society ever since the discovery of language. Human beings learnt how to communicate and knowledge transfer took place from father to son, teacher to pupil, from educated to the uneducated through various means as written form, songs and dances or by folklore. As long as society was not widespread, these different tools and techniques served its purpose of facilitating the transfer of knowledge.

In small organizations, which are geographically not spread out or which are psychologically close knit, knowledge dissemination takes place without any formal procedure in place. The grapevine is sufficient to ensure free flow of knowledge. However, a major drawback is that of the content being distorted as it moves away further from the originator. Today even in small organizations it is not possible to expect that each and every employee is aware of every bit of information existing or generated within the organization. 
The hectic pace of work and other professional demands leave us with very little time to frequently sit and discuss the latest updates. This lack of social networking also prevents us from knowing who knows what in our own organizations.

Large organizations suffer from a lack of cohesiveness and duplicates efforts because they have scattered or virtual units, flexi-hours and work from home options. Moreover the employees working in such organizations suffer from lack of self-esteem and do not show loyalty. In such cases although a large amount of knowledge will be generated, it will not be put to proper use due to lack of connectivity. An employee in the eastern region will not be aware of the developments in the western region. Hence knowledge dissemination will not take place.(Goswami, 2004)

The concept of knowledge management is to ensure that reinvention of the wheel does not take place, to ensure that we can build on what we learn from others and in the organizational context to ensure that the response time to adapt to environmental changes is reduced. In a highly competitive world where every unit of time is crucial and where every decision is strategic, it becomes imperative that an organizational repository of knowledge is generated and stored in an accessible place. What could be better than having a centralised database in an user friendly form !

The objective of knowledge management is to capture tacit knowledge of different stakeholders of the organization as customers, shareholders, employees, suppliers etc. and make it explicit so that other employees can take advantage of it. Such sharing of information will enable improved and quicker decision making and benefit the organization.

\section{Knowledge Management in India: Some examples}

India has witnessed Knowledge Management(KM) in practice by some companies. Goodlass Nerolac, paint-maker, embraced Knowledge Management in March 2003 because a need was felt to capture knowledge from purchase patterns of customers and dealer insights. Along with money paid for the product, customers also provide a lot of information as their perception of the product and similar substitute products. The strategic challenge lies in designing an interface which will permit easy trapping of customer information. Know Net - the knowledge management portal of Larson \& Toubro ( a construction company) was set up to solve problems occurring at project sites. It uses KM to roll out real world construction projects at lower costs. Each employee in the organization has accumulated experience over the years and has unknowingly used it for problem solving or creating strategies. The strategic challenge lies in getting people to know 'what they know' and then share it with others, make it articulate and explicit. Infosys Technologies (software producer) uses its KM 
system to capture and template permanently the learnings from projects because software professionals tend to be mobile (Goswami, 2004).

Infosys has conceived, developed and deployed internally an elaborate architecture for $\mathrm{KM}$, that aims to take the company to a 'Learn Once, Use Anywhere' paradigm. In mid 1999 a formal initiative for implementing KM was adopted and the vision was to 'enable every action by the power of knowledge, leverage knowledge for innovation, empower every employee by the knowledge of every other employee, and to be a globally respected knowledge leader'. The challenge is to create direct people-to-people sharing mechanism. (Kochikar, 2001)

Wipro Infotech has the following KM model. (Srivastava et al , 2001)

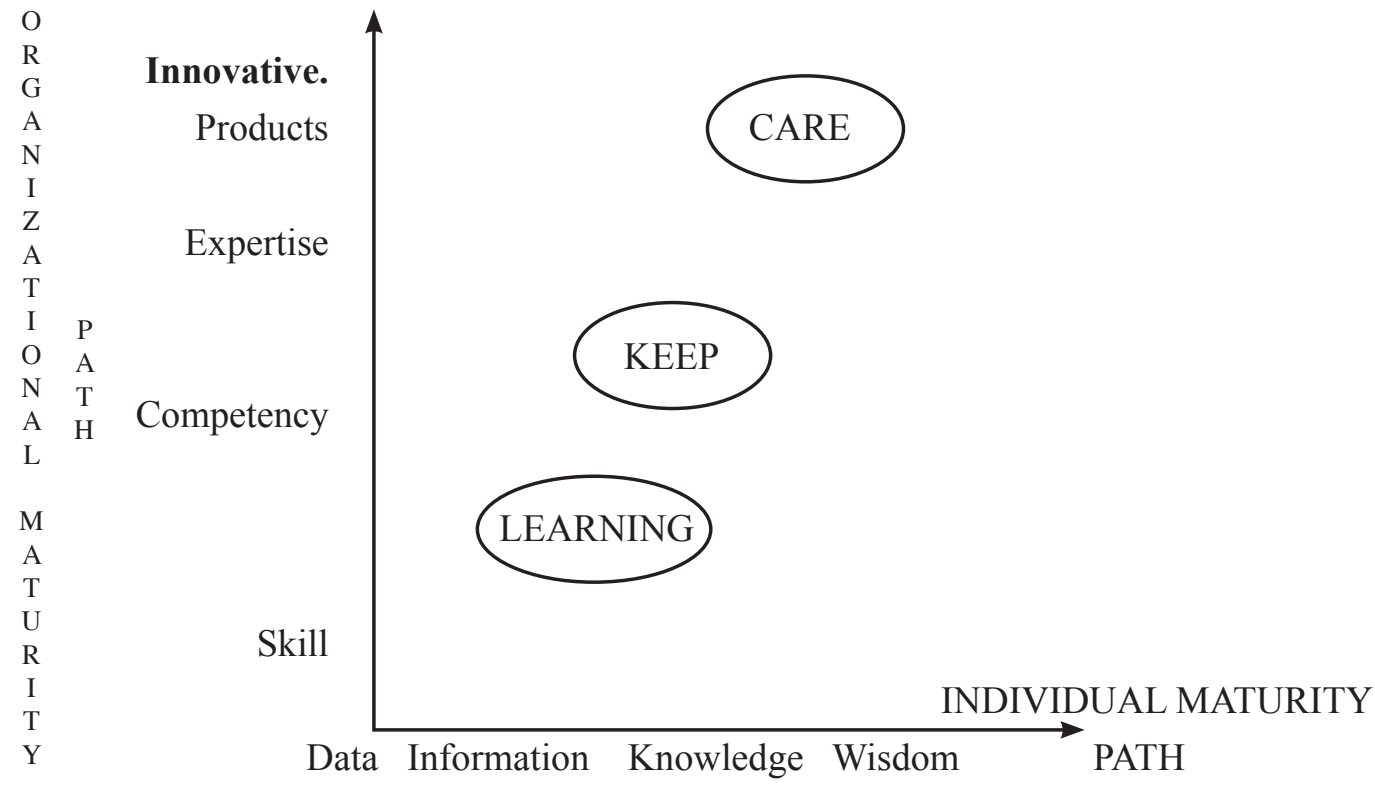

Fig:1 Wipro’s KM Model [Source: Srivastava et al , 2001 ]

\section{Learning Building Capacity}

Knowledge Extraction Enhancement \& Practice (KEEP) Collection of disparate knowledge and expertise within organization

Competency Augmentation through Research (CARE) Leverage on expertise and knowledge built up to come up with innovative products and services 


\section{KM at ICICI Bank}

The rapidly changing business environment and the constant challenges it poses to organizations and businesses makes it imperative to continuously enhance knowledge and skill sets across the organization. ICICI Bank believes that building a learning organization is critical for being competitive in products and services and meeting customer expectations.(Source: $8^{\text {th }}$ Annual report 2001-02, pg.65)

The ICICI portal "Wise Guy" was started because a need was felt to create and generate the culture of knowledge sharing. The need was sparked off by mass exodus of employees from their 'Treasury' moving towards the then greener pastures of the 'Dotcom Era'. Whenever an employee moves, he does not leave behind him documented information about the job or client that he was associated with. This causes a lot of botheration for the new incumbent. He spends most of his time trying to build a foundation and begin his work - in other words it is the reinvention of the wheel. Another reason for introduction of this concept could be due to the fact that the merger of ICICI with ICICI Bank was in the offing. The "Wise Guy" portal could act as a common thread binding two different cultures enabling a smooth transition into a universal bank. ICICI Bank has branches spread all over the country. There are employees who have interacted only via emails and have never seen each other. They function as a virtual team. There was a need to bring about a common platform for uniting the people across the country and foster a sense of belonging. This need was not being fulfilled by the existing Intranet.

\section{Initiating KM at ICICI}

Having being convinced about the need for practicing Knowledge Management, the next important step for management is to go about putting it into practice. In ICICI it started by having a Coordination Group who sold the concept to the employees. The 'Wiseguy' banner was floated in the company's Intranet; it eventually became a part of the Intranet. Emails were sent out to all employees about 'Wiseguy' and its features. Interested persons could get in touch with the system administrator for login password. The Coordination Group members comprised employees from the research group, HRD, ICICI infotech and the library staff. The concept initiated in April 2000. A dedicated team of 7 software developers worked on it using existing IT infrastructure. The first version went live on 15th June 2000 and the second was version made live on 15th October 2000. Between April and November it had 40,000 hits.

Intellect clearly resides inside the firm's human brains. Elements of knowledge, skills and understanding can also exist in the organization's systems, databases or operating 
technologies. If properly matched, intellect in each form is both highly leverageable and protectable.(Prahlad and Hamel, 1990)

An individual may possess knowledge by sheer virtue of her being associated with the organization. This knowledge that she possesses is tacit in nature. However the explicit part of the knowledge is when associates know that she has knowledge about a particular thing. It is this tacit knowledge that has to be captured, codified and put in a common place from where all in the organization can have access and utilise it to their benefit. This is easier said then done. The first problem that is likely to crop up is the unwillingness of the owner of the knowledge to part with it. The second problem would be when the owner is willing to articulate it but the recipient is unwilling to absorb it.

The "Wise Guy" portal began with articulation of those information which were explicit to only a few persons in the organization and tacit in general. No person was asked to share his/her tacit knowledge at this point. Sharing of such explicit information did not threaten anybody's knowledge quotient and nor did anybody lose any personal power which comes from being knowledgeable in a particular area. Thus the contents of the portal were discussions, queries, edited contributions, books, training calendar, vendors, external and internal reports, events, and captured offline lectures/presentations.

\section{The "Wiseguy" at ICICI}

When the site was introduced, awareness was generated by sending mails to all employees and by putting banners on the Intranet site, i.e. the 'universe'. In order to sustain interest in the site, efforts are being made to acknowledge the contributions made by the users. Every month the top three contributors are selected on the basis of the contributions made in the last three consecutive months. For e.g. the contributions made in January, February and March are judged for awards in April, while the contributions made in February, March and April are judged for awards in May. Awards are on the basis of the number of contributions made, number of people who read that article/write-up and number of responses given to different queries. Cash prizes (K-cash points) are given and photographs of the winners get a place for a week on the site. E-mails about the portal (both congratulatory and critical) are uploaded so that it generates discussion about the pros and cons of the system.

A personal corner exists on the Wiseguy, whereby one can save searches or track ones level of involvement on the Wiseguy or count K-cash points or update personal profile. The expertise that is mentioned in the profile helps in tracking people expertise wise. The people tracker can also track people on the basis of names, or departments or areas.

Each section in the Wiseguy can be accessed only if one has a login-id (which is 
usually the employee code) and a password. Confidential sections, which are not for public view, are restricted by the administrator. This helps in building privacy, which is essential for sections containing client information. This is similar to Lowe's (advertising agency) Mindstore (which permits general access) and Mindcircle (which permits restricted access) in the KM portal called Owle's World.

The 'Learning Matrix' lets one upgrade ones knowledge at ones own pace. Out of the currently available 83 plans, an employee can select a few modules which s/he would like to do in the given year. Some modules are compulsory for some departments/groups, while others are optional. The employee can keep track of what s/he has registered for, how many have been completed and how many are pending. The 'Scorecard' keeps a score of programs completed and certificates obtained. The electronic version of the certificate can also be printed.(Goswami, 2004)

The Corporate Information Bank provides Company Research and Industry Analysis. The site also provides links to other useful databases as the MIT knowledge base, ICRA database, Banking Rules etc. all aimed at empowering the employee to make a rational strategic decision. Client tracker and Business tracker, which have restricted access are helpful for new incumbent to the job to brief himself about the background of the client or the business in hand. However KM cannot be subservient to information technology. Thus the "Wiseguy" has a human face also. Knowledge events are arranged by the KM Group from time to time where people can get to interact with CEOs or CFOs or Experts in a formal meeting which is announced beforehand. If the branches desire, a webcast is also arranged. The presentation is recorded and later transferred to the KM site.

\section{Users' Perception about KM at ICICI}

KM will achieve its desired objective of contributing positively to strategy formulation only if there is whole hearted participation from the employees. A survey was conducted among 31 employees of ICICI Bank at Mumbai office. Their perception about $\mathrm{KM}$ are as follows: [Questionnaire in Annexure 1]

\section{Linkage of strategy with KM:}

(S1) Majority of the respondents agreed with the statement that a good business strategy depends on the internal knowledge base of the company.

(S2) Out of total $97 \%$ of the respondents felt there was indeed a link between strategy and the external environment.

(S3) Out of total 52\% felt that externally focussed orientation did not provide a secure foundation for formulating long term strategy. 
(S4) Out of total respondents $61 \%$ believed that the firm's own resources maybe a more stable basis to formulate a strategy.

It is evident from the findings that both schools of strategy are being followed in ICICI. One is that opportunities exist and therefore the organization must gear up to grab it and the second thought is that the company's internal strengths permit it to take advantage of a few specific opportunities. However, it is seen that the orientation is slowly moving towards the second and newer school of strategic planning and stress is being given on internal resources.

\section{Tangible vs Intangible resources:}

(S7) $84 \%$ of the respondents agree that the intangible assets of a firm provide an edge.

(S8) Opinion about which provides more competitive advantage; tangible or intangible; is fuzzy. $32 \%$ believe in tangible assets, $48 \%$ believe in intangible assets, while the rest are undecided.

From the statements one can perceive that both tangible as well as intangible assets are given equal importance, with a slight lean towards the intangible ones.

\section{KM and Profitability:}

(S9) $97 \%$ of the respondents believe that utilisation of the knowledge base of the company will result in reaping rich dividends.

(S10) $65 \%$ of the respondents disagreed with the statement that profits are not linked to employees' knowledge.

From the above statements, it can be observed that although majority believe that use of the company knowledge base would definitely yield dividends but they appear to be not very clear about each and every employee's contribution to profitability of the company.

\section{Knowledge Dissemination and Transferability:}

(S5) The respondents slightly disagreed that knowledge residing within an employee is difficult to replicate. Opinion seems to be divided in this matter with $46 \%$ feeling that it is not difficult to replicate, $45 \%$ feeling that it is difficult to replicate and $9 \%$ being undecided.

(S6) $52 \%$ disagreed with the statement that employees' knowledge base is easily transferable.

(S11) Majority of the respondents (94\%) disagreed that knowledge deteriorates if applied or shared.

(S12) All respondents were unanimous in their opinion that sharing or application of knowledge leads to enrichment of the knowledge base. 
From the above findings, one can observe that everybody seems to agree and believe in sharing and application of knowledge. Some feel that one can replicate (copy) another employees knowledge (methodology of working). However they disagree that the entire knowledge base of an employee can be easily transferred to another person or database.

In conclusion it can be said that emphasis is being given on the internal intangible resources of the company while formulating strategies. The ambience within the organization is that of willingness to share one's own experience and learn from other's experience. Knowledge dissemination and sharing is believed to lead to rich dividends but a direct link with profits is still not yet clear cut.

\section{Critical Success Factors}

Factor Analysis was done on the 16 factors that are believed to influence and promote knowledge management. These factors were selected after doing an extensive literature review. Exploratory factor analysis was conducted and the initial results of tests of sampling adequacy showed the following results.

Table: 1

KMO and Bartlett's Test

\begin{tabular}{|c|r|r|}
\hline Kaiser-Meyer-Olkin Measure of Sampling Adequacy. & & .444 \\
\hline Bartlett's Test of Sphericity & Approx. Chi-Square & 268.077 \\
\hline & $\mathrm{df}$ & 120 \\
\hline & Sig. & .000 \\
\hline
\end{tabular}

A KMO score of 0.6 is an acceptable score and therefore factors with low KMO statistic values were dropped till the overall KMO rose to near about 0.6 . Three factors were dropped and factor analysis was done on the remaining 13 factors.

Table:2 KMO and Bartlett's Test

\begin{tabular}{|c|c|c|}
\hline \multicolumn{2}{|c|}{ Kaiser-Meyer-Olkin Measure of Sampling Adequacy. } & 0.5613777 \\
\hline Bartlett's Test of Sphericity & Approx. Chi-Square & 190.0009 \\
\hline & Df & 78 \\
\hline & Sig. & 0 \\
\hline
\end{tabular}

Further dropping of factors did not improve the overall KMO statistic. Thus these 13 factors were considered for the analysis using the software SPSS. The method of Principal Component Analysis was used and the following results were obtained. 
Table:3 Communalities Table

\begin{tabular}{|l|r|r|l|l|l|}
\hline \multicolumn{2}{|c|}{ Communalities } & & & & \\
\hline & Initial & Extraction & & \\
\hline F2 & 1 & 0.4574 & & & \\
\hline F5 & 1 & 0.61557 & & & \\
\hline F6 & 1 & 0.7208 & & & \\
\hline F7 & 1 & 0.66967 & & & \\
\hline F8 & 1 & 0.74708 & & & \\
\hline F9 & 1 & 0.74407 & & & \\
\hline F10 & 1 & 0.75525 & & & \\
\hline F11 & 1 & 0.67425 & & & \\
\hline F12 & 1 & 0.77949 & & & \\
\hline F13 & 1 & 0.85184 & & & \\
\hline F14 & 1 & 0.58769 & & & \\
\hline F15 & 1 & 0.88682 & & & \\
\hline F16 & 1 & 0.7814 & & & \\
\hline Extraction Method: Principal Component Analysis. & \\
\hline \multicolumn{7}{|l|}{} \\
\hline \multicolumn{7}{|l|}{} \\
\hline
\end{tabular}

Table:4 Total Variance Explained

\begin{tabular}{|r|r|r|r|}
\hline & \multicolumn{2}{|c|}{ Initial Eigenvalues } & \\
\hline Component & \multicolumn{1}{|c|}{ Total } & \% of Variance & Cumulative \% \\
\hline 1 & 4.2341 & 32.56997197 & 32.569972 \\
\hline 2 & 2.00354 & 15.41180789 & 47.98178 \\
\hline 3 & 1.90269 & 14.63606456 & 62.617844 \\
\hline 4 & 1.13102 & 8.700136681 & 71.317981 \\
\hline 5 & 0.99754 & 7.673412952 & 78.991394 \\
\hline 6 & 0.70416 & 5.416641635 & 84.408036 \\
\hline 7 & 0.54761 & 4.212402311 & 88.620438 \\
\hline 8 & 0.47461 & 3.65085333 & 92.271291 \\
\hline 9 & 0.37113 & 2.854878957 & 95.12617 \\
\hline 10 & 0.26574 & 2.044188551 & 97.170359 \\
\hline 11 & 0.19034 & 1.464164003 & 98.634523 \\
\hline 12 & 0.1054 & 0.810743006 & 99.445266 \\
\hline 13 & 0.07212 & 0.554734163 & 100 \\
\hline Extraction Method: Principal Component Analysis. \\
\hline
\end{tabular}


Table:5 Data Reliability

R E L I A B I L I T Y A N A L Y S I S - S C A L E

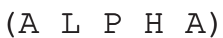
Reliability Coefficients

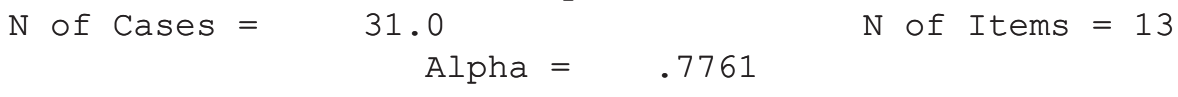

Table:6 Final Factors

\begin{tabular}{|l|r|r|r|r|}
\hline & Component & & & \\
\hline & 1 & 2 & 3 & 4 \\
\hline F2 & & & & \\
\hline F5 & & & & 0.6216 \\
\hline F7 & & 0.7962308 & & -0.7435 \\
\hline F8 & & & 0.6 & \\
\hline F9 & & & 0.793 & \\
\hline F10 & & 0.7189176 & & \\
\hline F11 & 0.641522407 & & & \\
\hline F12 & 0.877930967 & & & \\
\hline F13 & 0.878826598 & & & \\
\hline F14 & & & & \\
\hline F15 & & & 0.88 & \\
\hline F16 & & 0.8380426 & & \\
\hline $\begin{array}{l}\text { Extraction Method: Principal Component Analysis. } \\
\text { Rotation Method: Varimax with Kaiser Normalization. }\end{array}$ \\
\hline a Rotation converged in 9 iterations. & \\
\hline
\end{tabular}

Component 1 comprises of 'user friendly systems', 'attitude of employees', and 'willingness of employees to contribute'. This group maybe labeled as "Cooperation" which is expected both from the system developers and the users.

Component 2 comprises of 'peer recognition', 'attractiveness of the site' and 'need for reliable information'. This group maybe labeled as "Motivation Level".

Component 3 comprises of 'top management's involvement', 'management's pressure' and 'recognition from superior for contributing to site'. This group maybe labeled as "Top management support".

Component 4 comprises of 'work culture' and 'monetary incentive'. It is observed that 46 
monetary incentive shows a negative correlation, indicating that monetary incentive is not a prominent factor. This group maybe labeled as "Work culture".

These four groups account for $71 \%$ of the variation and can account for the progress of Knowledge Management. The data reliability score alpha is $77 \%$ which is at an acceptable level.

Thus we can conclude that for KM to thrive, the above mentioned factors i.e. Cooperation, Motivation Level, Top Management Support and Work Culture have to play a prominent role.

\section{Teething Problems Of KM}

Implementing $\mathrm{KM}$ is not hassle free. One can expect to face problems right from the conceptual stage. If the top management is not sold about the necessity for having KM then it will be difficult to emulate success. It will require a company sponsor who will champion for the cause of knowledge management. Such an advocate of KM is essential to maintain its importance. In case of ICICI, the Executive Director provided the initial thrust and it has been observed that the Chief of the KM Group reports to him directly. This is a positive signal sent across the organization that the top brass is serious about KM.

Another problem arises in getting people to genuinely contribute their knowledge and also in getting people to utilise information on the site. A very high level of constant motivation is required to get the entire organization hooked to the concept of searching for strategic information on the KM site. What the KM group did was to ensure that the Wiseguy contained enough information to be able to catch and retain the interest of a diverse interest group. In some cases, it was the daily capsule of the business news which hooked them while in other cases it was the business cartoons. Once a person got into the habit of daily logging in, he started browsing out of curiosity. This gave him an awareness of the different information sources available that he could use in course of his work.

Implementing KM requires money. The fund requirement depends on the kind of computer architecture that one proposes to use or has in place, the software needed and staffing requirements of the KM group. ICICI used the following architecture in its initial stages.

\section{HARDWARE}

$\varnothing$ COMPAQ PORLIANT SERVER

$\varnothing$ INTEL III WITH 512 MB RAM

\section{SOFTWARE}

$\varnothing$ WINDOWS NT SERVER V4.0

$\varnothing$ MICROSOFT SEARCH 
$\varnothing \quad$ JAVA APPELATES

The infrastructure, as in June 2003, comprised of two normal dedicated servers for developmental work and a production server. Both were web cum application servers. The software used were MS Active Server pages(ASP), Vbasic, Internet Information Server, MS SQL server 2000 and Windows $\mathrm{NT}(\mathrm{O} / \mathrm{S})$.

\section{Consequences of "Wiseguy"}

Wiseguy has contributed to the organization in the following ways.

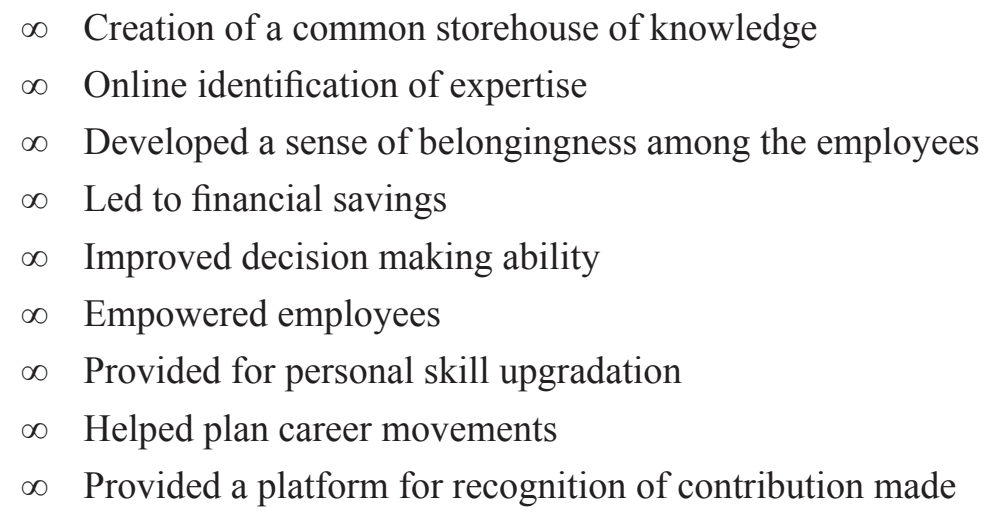

To a large extent it is seen that these fulfill the needs of the technical and professional workforce by giving them a platform for airing their views, contributing as well as upgrading their expertise, a chance for public recognition and planning upward mobility. It has also achieved in being a learning organization.

\section{Conclusion}

$\mathrm{KM}$ at ICICI began on an experimental basis and carried on expanding and exploring, widening its ambit of operations. No additional funding was required and nobody was under compulsion to use the site. The relatively young age group of the employees and support provided by the top management had led to the progress of the concept of knowledge management. It has not made any model to follow unlike Wipro has done. At present it is in a state of growth and flux and new sections and links are being added in the Wiseguy. Maybe in the next couple of years it will begin to consolidate and clearly define its objective of existence or else merge into the Intranet and be a part of corporate communications. 


\section{References}

Boisot Max H., (1995), "Is Your Firm a Creative Destroyer? Competitive Learning and Knowledge Flows in the Technological Strategies of Firms.”; Research Policy, Vol 24, 1995, pp 489-506.

Collis David J. and Cynthis A. Montgomery,(1995), "Competing on Resources: Strategy in the 1990s"; Harvard Business Review, July-August , pp118-128

Goswami Chandana, (2004). "Managing the Technical, Professional Workforce: Can Knowledge Management be the answer?"; In: Managing Trade, Technology and Environment (M. Mallikarjun and Pawan K. Chugan Ed.), pp 362-372, Excel Books, India

Grant Robert M., (1996). "Prospering in Dynamically-Competitive Environments: Organizational Capability as Knowledge Integration"; Organization Science, Vol.7, No.4, pp375-387

Grant Robert M., (1991). "The Resource-Based Theory of Competitive Advantage: Implications for Strategy Formulation”; California Management Review, Vol.33, Spring , pp114-135

Kochikar V.P.(2001). "Creating the KM Infrastructure at Infosys: The Technology Challenge”; Management Review, Vol 13, No.4, pp 104-110

Liebeskind Julia Porter, (1996). "Knowledge, Strategy, and the theory of the firm"; Strategic Management Journal, Vol.17, Winter Special Issue, pp93-107

Prahlad C.K. and Gary Hamel, (1990). "The core competence of the Corporation"; Harvard Business Review, May-June, pp79-91

Quinn James Brian, Philip Anderson, and Sydney Finklestein, (1996). "Leveraging Intellect"; Academy of Management Executive, Vol.10, No.3, pp7-27

Saint-Oge Hubert, (1996). "Tacit Knowledge: The key to the Strategic Alignment of Intellectual Capital"; Strategy and Leadership, March/April , pp10-14

Sangameshwaran Prasad, (2003). "Knowledge Management”; Indian Management, May, pp 31-35

Srivastave Anurag, N. Rajendhiran, Nandini Prasanna, Satish Prasad, (2001). "KM in Wipro Infotech - A case review"; Management Review, Vol 13, No.4, pp 111 - 116 